\title{
THEA-CODE: a design tool for the conceptual design of hybrid-electric aircraft with conventional or unconventional airframe configurations
}

\author{
Giuseppe Palaia ${ }^{1, *}$, Davide Zanetti ${ }^{2}$, Karim Abu Salem ${ }^{1}$, Vittorio Cipolla ${ }^{1}$, and Vincenzo Binante ${ }^{2}$ \\ ${ }^{1}$ University of Pisa, Department of Civil and Industrial Engineering, Pisa, Italy \\ ${ }^{2}$ SkyBox Engineering S.r.l., Pisa, Italy
}

Received: 30 July 2020 / Accepted: 11 February 2021

\begin{abstract}
The aviation world is dealing with the development of new and greener aviation. The need for reducing greenhouse gas emission as well as the noise is a critical requirement for the aviation of the future. The aviation world is struggling with it, and a compelling alternative can be the electric propulsion. This work aims to present THEA-CODE, a tool for the conceptual design of hybrid-electric aircraft. The tool evaluates the potential benefits of the electric propulsion in terms of fuel burnt and direct and indirect $\mathrm{CO}_{2}$ emissions. THEACODE is suitable not only for conventional "wing-tube" configurations but also for unconventional ones, such as the box-wing. The results show a significant reduction of fuel burnt adopting batteries with energy density higher than the current state of the art. A procedure to find the potential best compromise configurations is presented as well.
\end{abstract}

Keywords: Prandtl plane / hybrid-electric configuration / conceptual design / regional aircraft / electric propulsion / climate change / green aviation

\section{Introduction}

The climate is changing, and it is mainly related to man activity [1]. In the last UN Climate Change Conference, held in Madrid, the European Union showed its will to reduce noxious emission within 2050 [2]. To decrease the $\mathrm{CO}_{2}$ and the $\mathrm{NO}_{\mathrm{x}}$ emissions and to reduce the greenhouse gas effects, a strong technological improvement is compulsory in all sectors, aviation included [3]. Nowadays, the aircraft $\mathrm{CO}_{2}$ emissions are about $2.7 \%[4,5]$ of the total world emissions; moreover, the aviation demand is growing $4.5 \%$ per year $[6,7]$, and its contribution to greenhouse gas emissions will increase if real counteractions will not be undertaken. As stated in [8-10], the aviation of the future must reduce $\mathrm{CO}_{2}$ emission per passenger kilometre by $75 \%$, $\mathrm{NO}_{\mathrm{x}}$ emissions by $90 \%$ and the perceived noise emissions of flying aircraft by $65 \%$. To satisfy the all new requirements, a technological breakthrough in all aviation sectors is necessary, from aircraft configurations (to enhance the aerodynamic efficiency) to propulsion architectures (by using sustainable low-carbon fuels and alternative

\footnotetext{
* e-mail: giuseppe.palaia@phd.unipi.it
}

sources of energy as the electrical one) [9,10]. Currently, a lot of projects funded by the EU's Horizon 2020 research programme are ongoing to develop technological enhancements in these fields [11-13]; this public funding shows the great effort to move the aviation toward a greener transportation. Battery-powered electric aircraft can be a compelling alternative to the current carbon based fuel aircraft [14]: ideally, full-electric aircraft can remove the direct $\mathrm{CO}_{2}$ emissions and reduce noise during the take-off [5]. Although a full-electric aircraft can have many benefits, in particular for its zero-emission, the indirect $\mathrm{CO}_{2}$ emissions for electrical energy production must be considered in a complete analysis [15]. Nowadays, the biggest barrier for total aircraft electrification is the low energy density of the batteries: the energy density of the Li-ion battery is about $250 \mathrm{Wh} / \mathrm{kg}$, but, for regional transportation, a minimum value of about $800 \mathrm{Wh} / \mathrm{kg}$ would be necessary $[5,14-16]$. However, power electronics, electrical motors and batteries are technologically moving forward, and, in the next decades, hybrid-electric aircraft would be reasonably achievable [5,15-18]. The mixing of electrical and thermal propulsion paves the way to new propulsion architectures which must be investigated at the early stage of the design process. Differently from the classical aircraft 


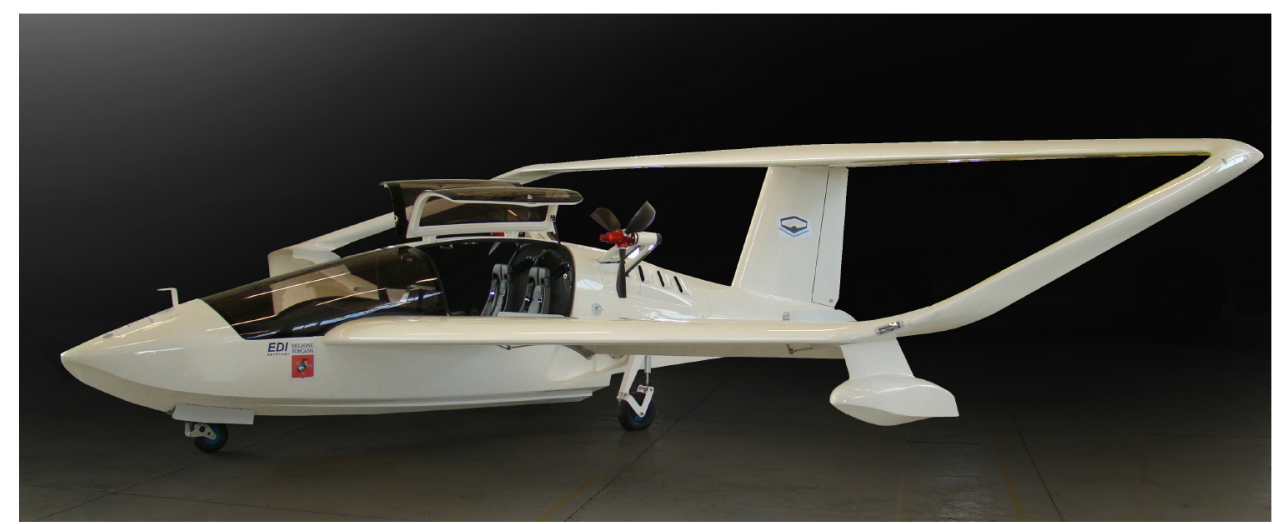

Fig. 1. An example of Prandtl Plane configuration developed during the IDINTOS project for a light amphibious aircraft [28].

design procedures, statistical data to predict fuel consumption can not be used to analyse hybrid-electric aircraft; in fact, battery and fuel mass do not depend only on the energy demand to accomplish the mission but also on the energy management strategy. The technological level of the electrical components is the most important factor which influences the feasibility of hybrid-electric aircraft. The technological level indicates the specific power and the energy density of the components which the designer must consider for a preliminary assessment of the mass, namely: power electronics, batteries and electrical motors. As said before, several hybrid-electric architectures can be exploited, namely: parallel, serial, parallel-serial partial, and turbo-electric $[15,16]$. Due to the constraint on energy density of the batteries, the electrification of single-aisle aircraft for the short-medium range is really far; a possible path for the electrification is the development of fullelectric aircraft for general aviation and turbo-electric and hybrid-electric for regional market [5,14]. Currently, a lot of works focus on this aircraft category: in reference [20,21], a turbo-electric architecture is coupled with a distributed electric propulsion; in reference [22], a procedure for sizing hybrid-electric architectures and for the energy management strategy is described. In reference [23,24] a conceptual design of hybrid-electric aircraft has been presented. Some authors have defined a multidisciplinary optimization framework, as in [25], to design a single aisle aircraft with distributed electric fans. All the previous works only consider hybridization of tube-and-wing configuration whereas hybridization of disruptive configurations (e.g. box-wing, blended wing-body) are not well studied yet.

This work aims to present a new design tool which can deal with disruptive configurations such as the PrandtlPlane. The Prandtl Plane (PrP) is a box-wing which, with a proper lift distribution, exhibits the lowest induced drag with respect to other lifting configurations with same wingspan and lift [26,27]. An example of Prandtl Plane configuration is depicted in "Figure 1".

THEA-CODE (Tool for Hybrid Electric Aircraft COnceptual DEsign) is a tool, developed in MATLAB ${ }^{\circledR}$, which allows to perform the design of a hybrid-electric aircraft (HEA) with a conventional and unconventional airframe. It has been developed within the Italian research project "PROSIB" which concerns the study of hybrid propulsion applied to fixed and rotary-wing aircraft. In the first part of the paper the general design procedure has been described; in the second part the main outputs for $\operatorname{PrP}$ configurations are detailed. In the last part, a qualitative procedure for the choice of the best compromise configuration is described.

\section{Hybrid architecture definition}

In the hybrid-electric scenario, several propulsion architectures exist. A comprehensive description of hybridelectric architectures and electric components are detailed in $[15,16]$; the two main architectures are serial and parallel configuration (see "Fig. 2"):

- Serial: a turboshaft moves an electric generator which, in conjunction with the batteries, generates electric energy to feed the electric motor directly or through a gearbox (GB) coupled with the propeller/fan;

- Parallel: a turboshaft in conjunction with an electric motor (fed by the battery) moves a propeller/fan by a gearbox.

By a combination of them, it is possible to obtain different architectures (e.g. serial/parallel partial hybrid). Nevertheless, in this paper only the two main architectures have been analysed. An important parameter is the degree of hybridization $\left(\mathrm{H}_{\mathrm{P}}\right)$, here defined in equation (1).

$$
\mathrm{H}_{\mathrm{P}}=1-\frac{\mathrm{P}_{\mathrm{ICE}}}{\mathrm{P}_{\mathrm{TOT}}}
$$

It indicates how much power comes from the electrical chain with respect to the total power of the propulsion system. The installed thermal power $\left(\mathrm{P}_{\mathrm{ICE}}\right)$ is the power supplied by the internal combustion engine; $\mathrm{P}_{\text {TOT }}$ is the total power supplied by the propulsion system. If $\mathrm{H}_{\mathrm{P}}$ is zero, no batteries are on board; if $\mathrm{H}_{\mathrm{P}}$ is equal to one, no internal combustion engine is on board. The two architectures show a slight difference for zero-degree of hybridization: the parallel architecture becomes a 


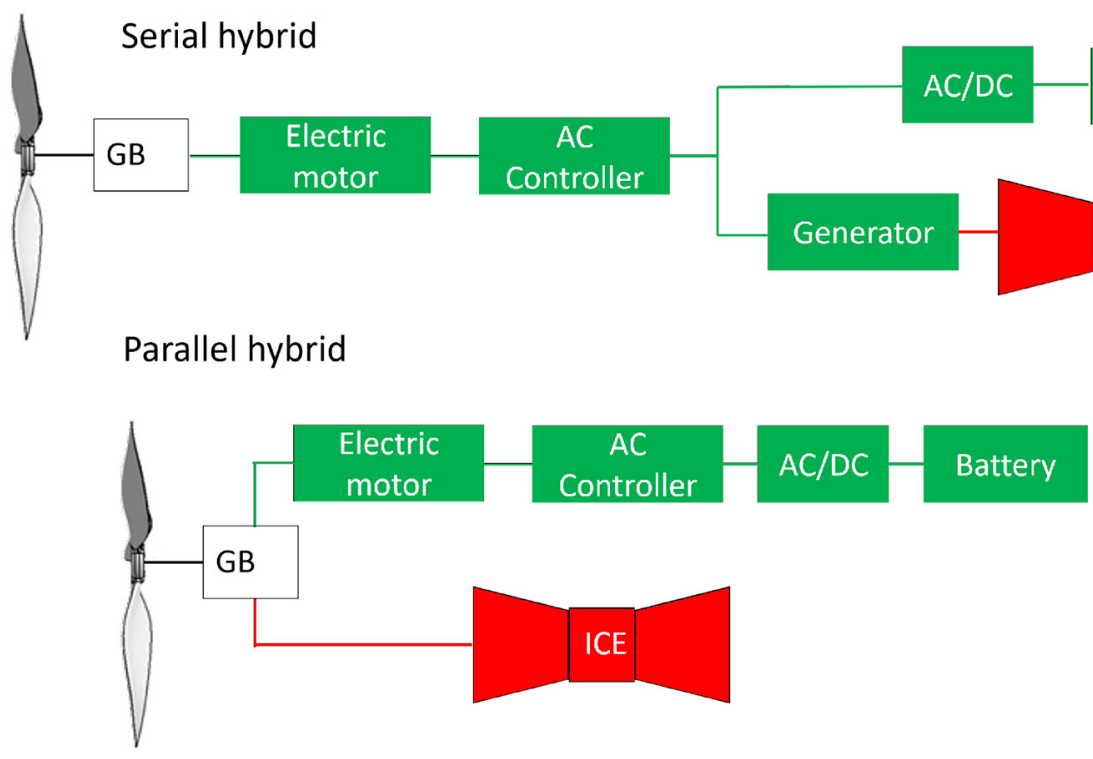

Fig. 2. Serial and parallel hybrid architecture.

conventional turboprop aircraft, and the serial one becomes a turboelectric aircraft.

\section{THEA-CODE}

The Maximum Take-Off Mass (MTOM) estimation is a crucial point in the aircraft design process. A correct estimation is even more thorny for a hybrid-electric aircraft because of the strong influence of the electrical system; in fact, the MTOM estimation strongly depends on the adopted hybrid architecture, such as serial or parallel $[14,29]$.

The developed design procedure deals with the MTOM prediction for hybrid-electric aircraft taking all the main aspects of the aircraft design into account: aerodynamics, engine sizing, mission analysis and weight estimation. Referring to the "Figure 3", the MTOM is estimated by means of an iterative cycle. The main subblocks are:

- "Aerodynamics" which allows the evaluation of the aircraft drag polar through a Vortex-Lattice method and viscous drag coefficient estimation;

- "Aircraft constraints" which defines the power required to both thermal engine and electric motor;

- "Mission performance" which evaluates the required fuel and battery mass;

- "Weight estimation" which evaluates the Operative Empty Mass (OEM) of the aircraft, the passenger mass and the mass related to fuel and batteries.

The developed procedure allows the designer to analyse multiple configurations, so an important parameter to take from the conceptual design phase into account is the degree of hybridization; in fact, as shown in [29], it is a sensitive parameter to evaluate the aircraft emissions.

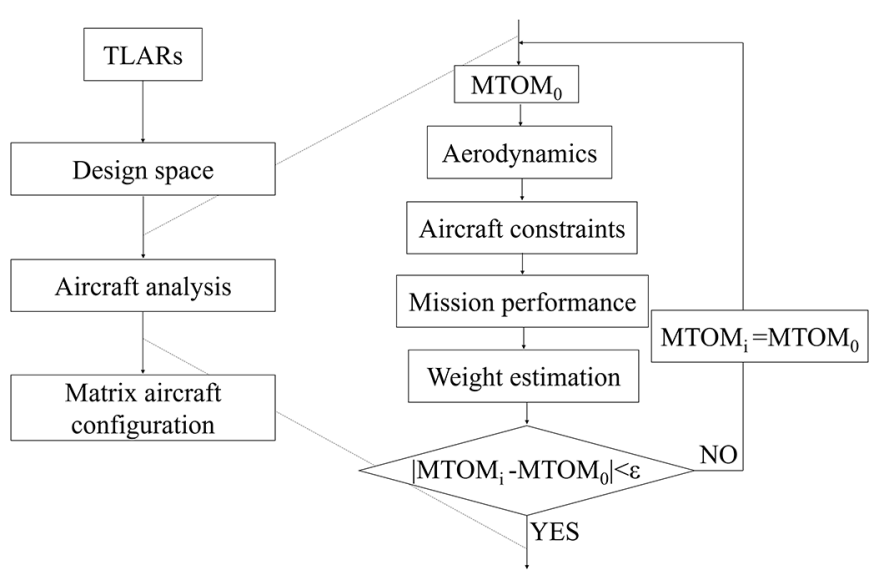

Fig. 3. Workflow of THEA-CODE.

The evaluation of the engine sizing is strictly related to the fulfilment of the requirements coming from TLARs and FAR, and they can be easily depicted in the matching chart of specific power (P/MTOM)-wing loading $(\mathrm{MTOM} / \mathrm{S})$; through it is possible to define a region of feasible design space with respect to the constraints coming from the Top-Level Aircraft Requirements (TLARs) and the Federal Aviation Regulation (FAR).

As depicted in "Figure 4", the green region shows all the combinations of specific power and wing loading which fulfil all the constraints. In case of HEA, the total power can be shared between the electric and thermal chain, and the power repartition depends on the degree of hybridization. If the degree of hybridization increases, the power supplied by the internal combustion engine makes smaller, and the electric power increases. If $\mathrm{H}_{\mathrm{P}}$ is equal to zero, the parameters (wing loading and specific power) locate a point ( 1 in "Fig. 5") on the chart, and no hybridization is 


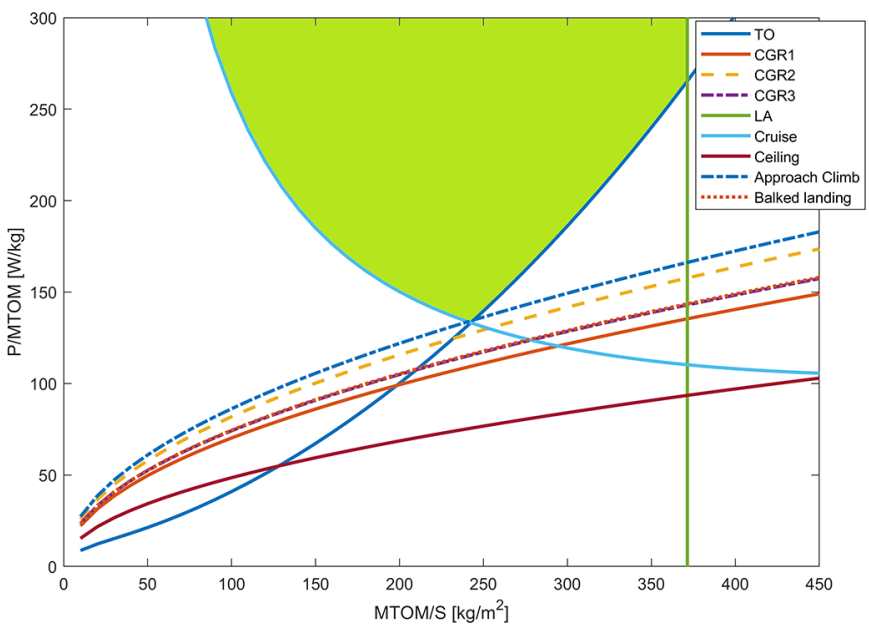

Fig. 4. Example of matching chart of specific power versus wing loading. The green region is the feasible design space.

considered. If $\mathrm{H}_{\mathrm{P}}$ is lower than one, the parameters locate a point ( $\mathbf{\Lambda}$ in "Fig. 5") which corresponds to a hybrid configuration; in this case the power is split according to the $\mathrm{H}_{\mathrm{P}}$ value. If $\mathrm{H}_{\mathrm{P}}$ is equal to one, the parameters locate a point (- in "Fig. 5") corresponding to a full-electric configuration.

By means of the chart in "Figure 5", the designer can examine all the design space thanks to two parameters: the wing loading and the degree of hybridization: the ranges of these two parameters define the design space. The output of THEA-CODE is a response surface in terms of wing loading and degree of hybridization which can be easily used to determine the feasible and unfeasible regions and to evaluate the best configurations in terms of minimum fuel burnt, MTOM or $\mathrm{CO}_{2}$ emissions.

\subsection{TLARs and design space}

THEA-CODE deals with the conceptual design of HEA. As shown in "Figure 3", the TLARs are given in the first block of the workflow; they define the set of the requirements to be fulfilled, namely: the number of passengers, the cruise and speed altitude and take-off and landing field length. The second block of the workflow is the design space; as said before, the design space is defined by the combination of two parameters: the wing loading and the degree of hybridization. By changing these two parameters, it is possible to evaluate a large set of configurations. In the aircraft design procedure of HEA it is very important to evaluate also the sensitivity to the electrical components, so the battery energy density (BED) must be considered as an additional parameter to take into account. In this paper, three different technological levels have been considered: 500,1000 and $1500 \mathrm{Wh} / \mathrm{kg}$ according to the literature [15-19].

\subsection{Aerodynamics}

The aerodynamics module calculates the drag polar of the configuration by using the software AVL [30], XFOIL [31]

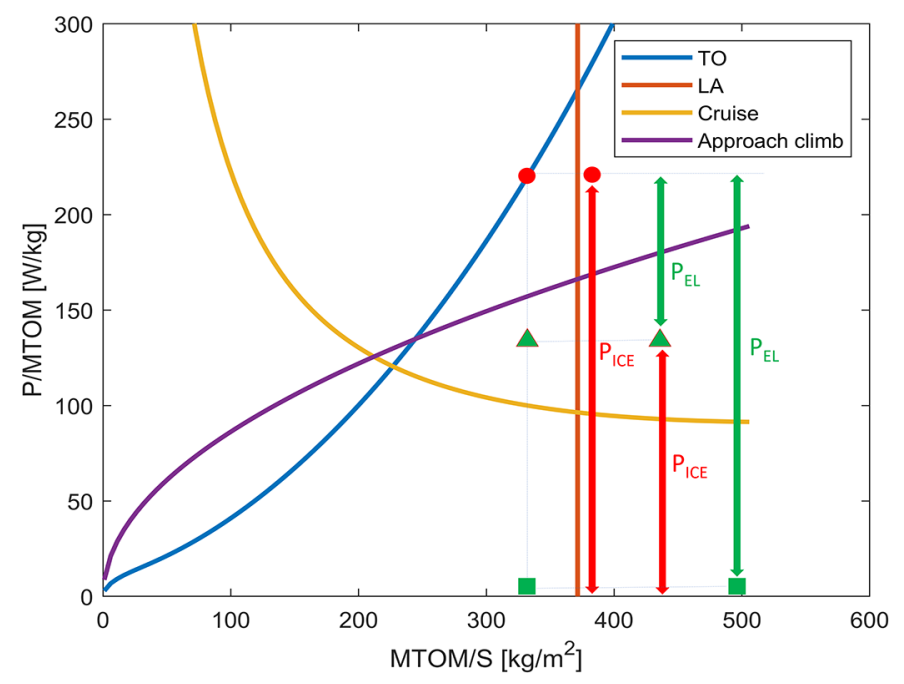

Fig. 5. Repartition of electric and thermal power for a thermal propulsion aircraft $(\bullet)$, HEA $(\mathbf{\Delta})$ and full-electric $(\bullet)$ with a parallel architecture.

and the component build-up method described in [32]. The total drag can be decomposed in the sum of the subcomponents drag:

$$
D_{\text {tot }}=D_{\text {wing }}+D_{\text {fin }}+D_{\text {fuselage }}+D_{\text {nacelle }}
$$

The nacelle and fuselage drag has been calculated according to the component build-up method. The wing induced drag has been calculated by means of AVL (see Fig. 6) whereas the main wings and fin parasitic drag has been computed by extending the XFOIL results on the entire surface according to the equation (3).

$$
\mathrm{D}_{\mathrm{f}}=\varrho \mathrm{V}^{2} \int_{0}^{\bar{y}} \mathrm{C}_{\mathrm{d}}(\mathrm{y}) \mathrm{c}(\mathrm{y}) \mathrm{dy}
$$

where $D_{f}$ is the wing parasitic drag; $\varrho$ is the air density; $V$ is the speed; $\mathrm{c}$ is the chord distribution along the span $(\bar{y})$, and $\mathrm{C}_{\mathrm{d}}$ is the airfoil drag. Starting from a reference geometry, the aerodynamic polar can be calculated for any configuration.

\subsection{Aircraft constraints}

The module "Aircraft constraints" defines the main constraints which the propulsion system must satisfy. The equations define a relationship between the specific power and the wing loading; these constraints have been defined according to the relations defined in [33], but properly modified for a propeller-driven aircraft [34]. The constraints are based on the FAR 25 [35], and an example of the chart is depicted in "Figure 4". As described in [33], all the requirements can be defined by mathematical expressions; the relationship used in the paper are defined 

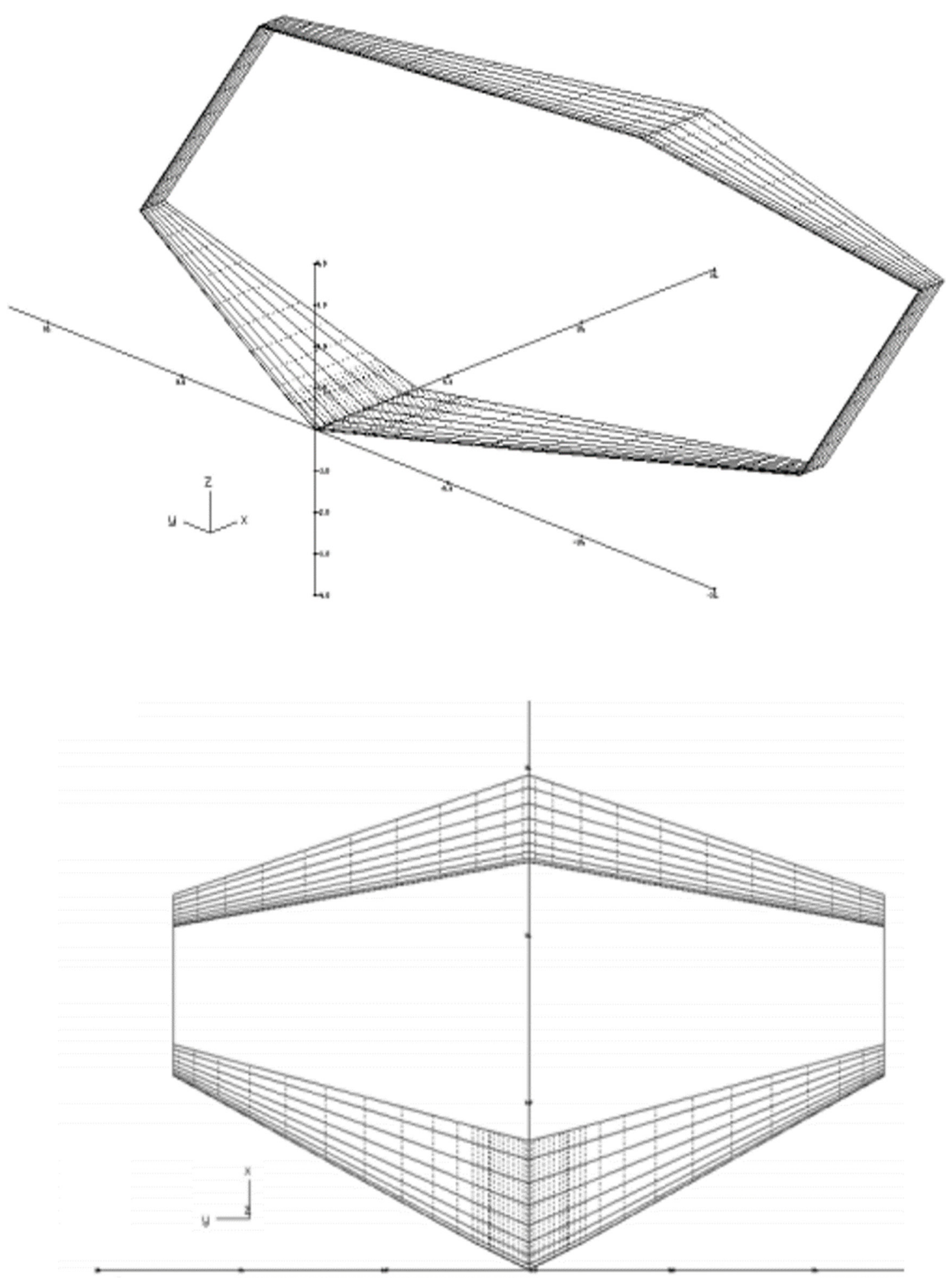

Fig. 6. An example of Prandtl Plane wing configuration defined in AVL for the THEA-CODE workflow. 
as follows:

$$
\begin{aligned}
& \left(\frac{\mathrm{P}}{W}\right)_{\mathrm{TO}} \geq\left(\mu+\frac{\frac{\mathrm{k}_{\mathrm{V}_{\mathrm{R}}}^{2}\left(\mathrm{C}_{\mathrm{D}}-\mu \mathrm{C}_{\mathrm{L}}\right)}{\mathrm{C}_{\mathrm{Lmax}}}}{1-\mathrm{e}^{-\rho \mathrm{g}\left(\mathrm{C}_{\mathrm{D}}-\mu \mathrm{C}_{\mathrm{L}}\right)\left(\frac{\mathrm{L}_{\mathrm{TO}}}{\sigma}-\mathrm{S}_{\mathrm{R}}-\mathrm{S}_{\mathrm{LO}}\right) /(\mathrm{W} / \mathrm{S})}}\right) \\
& \times \sqrt{\frac{2(\mathrm{~W} / \mathrm{S})}{\rho \mathrm{C}_{\mathrm{Lmax}}}} \mathrm{k}_{\mathrm{V}_{2}} \\
& \left(\frac{\mathrm{P}}{W}\right)_{i} \geq\left(\frac{\frac{1}{2} \rho \mathrm{C}_{\mathrm{D}} \mathrm{V}_{i}^{3}}{\frac{\mathrm{W}}{S}}+\gamma_{i} \mathrm{~V}_{i}\right)
\end{aligned}
$$

The equation (A.1) has been used for the take-off phase, and it is described more deeply in the appendix; the equation (A.2), obtained by using the classical flight mechanics equations, has been used for several phases, namely: cruise, take-off flight path with one engine inoperative, approach climb and landing climb. The take-off flight path, approach climb and landing climb follow the FAR 25.111, FAR 25.121 and FAR 25.119, respectively. All the requirements are drafted in Figure 4: more in details the three terms CGR1, CGR2 and CGR3 refer to the three phases (CGR1 to the first phase, CGR2 to the second phase, CGR3 to the last phase) during the takeoff flight path; the approach climb and the balked landing refer to the approach climb and landing climb. The output of the "Aircraft constraints" block is the specific power to be installed, which is the minimum power to satisfy all the requirements, and it is defined by the equation (4).

$$
\left(\frac{\mathrm{P}}{W}\right)_{\text {inst }}=\max \left(\left(\frac{\mathrm{P}}{W}\right)_{\mathrm{TO}},\left(\frac{\mathrm{P}}{W}\right)_{i}\right)
$$

\subsection{Mission performance}

Fuel and battery are the sources of energy for a hybridelectric aircraft. They can be used, together or not, to feed the thermal engine or the electric motor for each flight phase. In this paper, the following strategy of energy source management has been adopted:

- For each flight phase, the power $\left(\mathrm{P}_{\mathrm{REQ}}\right)$ to accomplish the flight phase has been calculated;

- Calculation of the net power supplied by the internal combustion engine $\left(\mathrm{P}_{\mathrm{ICE}} \eta_{\mathrm{ICE}}\right)$;

- If $\mathrm{P}_{\mathrm{ICE}} \eta_{\mathrm{ICE}}<\mathrm{P}_{\mathrm{REQ}}$, the battery pack supplies power; conversely, the only thermal chain supplies power.

This strategy implies that the quantity of the electrical energy changes for each phase of the mission; taking as example the HEA in "Figure 5", the battery does not supply power during the cruise.

The output of the "Mission performance" block is the battery and fuel mass necessary to accomplish the entire mission. The energy demand has been calculated according to the standard flight mechanics equations [36]. The battery

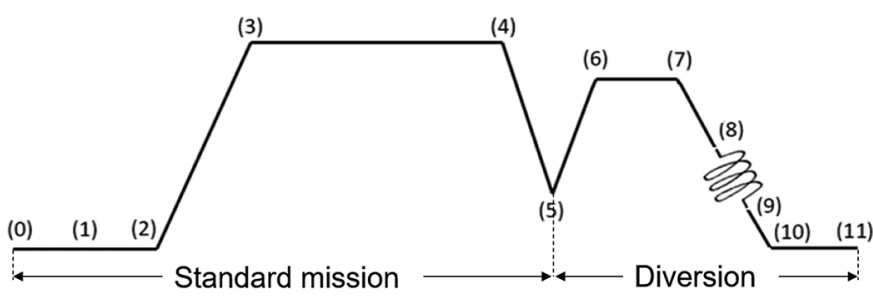

Fig. 7. Typical mission for a transportation aircraft category.

Table 1. General assumptions for each flight phase of the mission.

\begin{tabular}{lll}
\hline \multicolumn{2}{l}{ Mission phase } & Assumption \\
\hline $0-1$ & Taxiing & 7\% of the maximum power \\
$1-2$ & Take-Off & Maximum power \\
$2-3$ & Climb & Best rate of climb \\
$3-4$ & Cruise & Constant speed and altitude \\
$4-5$ & Descent & Constant rate of descent \\
$5-6$ & Climb & Best rate of climb \\
$6-7$ & Cruise & Constant speed and altitude \\
$7-8$ & Descent & Constant rate of descent \\
$8-9$ & Loiter & 30 min at minimum power \\
$9-10$ & Approach & Constant rate of descent \\
$10-11$ & Landing & Neglected \\
\hline
\end{tabular}

mass has been evaluated according to the battery energy density selected, and the equations used for the energy demand have been properly modified for the HEA. In equation (5), the relationship adopted for the cruise phase have been displayed.

$$
\left\{\begin{array}{l}
\frac{\mathrm{dW}}{\mathrm{dt}}=-\mathrm{PSFCP}_{\mathrm{ICE}} \\
\mathrm{L}=\mathrm{W} \\
\mathrm{P}=\mathrm{DV} \\
\mathrm{P}_{\mathrm{ICE}} \eta_{\mathrm{ICE}}+\mathrm{P}_{\mathrm{BATT}} \eta_{\mathrm{EL}}=\mathrm{P} \\
\mathrm{H}_{\mathrm{P}}=1-\frac{\mathrm{P}_{\mathrm{ICE}}}{\mathrm{P}_{\mathrm{TOT}}}
\end{array}\right.
$$

$\mathrm{W}$ is the weight of the aircraft; PSFC is the power specific fuel consumption; $\mathrm{L}$ is the lift; $\mathrm{P}$ is the requested power to accomplish the flight phase, and $\mathrm{D}$ is the drag.

The mission considered for a transportation aircraft is depicted in "Figure 7", and the assumptions for each flight phase are detailed in Table 1.

It is worth to note that the calculation of the fuel and battery mass is fundamental since statistical data do not exist yet, and a right evaluation is compulsory to calculate the total mass of the aircraft.

\subsection{Weight estimation}

The aircraft MTOM is calculated by the equation (6).

$$
\begin{aligned}
\mathrm{MTOM}= & \mathrm{M}_{\mathrm{STRUCT}}+\mathrm{M}_{\mathrm{SYS}}+\mathrm{M}_{\mathrm{OPIT}}+\mathrm{M}_{\mathrm{PAY}} \\
& +\mathrm{M}_{\mathrm{PRO}}+\mathrm{M}_{\mathrm{FUEL}}+\mathrm{M}_{\mathrm{BATT}}
\end{aligned}
$$


Table 2. Efficiencies of the thermal and electrical chains for serial and parallel hybrid architecture.

\begin{tabular}{lll}
\hline & Serial & Parallel \\
\hline$\eta_{\mathrm{EL}}$ & $\eta_{B} \eta_{\text {esc }} \eta_{\text {mot }} \eta_{\text {gb }} \eta_{\text {prop }}$ & $\eta_{B} \eta_{\text {esc }} \eta_{\text {mot }} \eta_{\text {gb }} \eta_{\text {prop }}$ \\
$\eta_{\text {ICE }}$ & $\eta_{\text {gen }} \eta_{\text {esc }} \eta_{\text {mot }} \eta_{\text {gb }} \eta_{\text {prop }}$ & $\eta_{\text {gb }} \eta_{\text {prop }}$ \\
\hline
\end{tabular}

The structural mass $\left(\mathrm{M}_{\mathrm{STRUCT}}\right)$, the subsystem mass $\left(\mathrm{M}_{\mathrm{SYS}}\right)$ and the operating item mass $\left(\mathrm{M}_{\mathrm{OPIT}}\right)$ have been calculated according to the procedure described in [37]. In this procedure, statistical data and empirical formula have been used for the mass prediction of tube-and-wing aircraft, and no unconventional aerodynamic configurations have been considered. Due to this lack, the two lifting surfaces of the box-wing have been considered as cantilever wings (no interaction between them from a structural point of view), to have conservative results. This approach will be improved in the future, introducing a parametric model specifically developed for the case of interest. The payload mass $\left(\mathrm{M}_{\mathrm{PAY}}\right)$ comes from the TLARs assuming a $95 \mathrm{~kg} /$ passenger (including baggage). The propulsion system mass $\left(\mathrm{M}_{\mathrm{EL}}\right.$ and $\left.\mathrm{M}_{\mathrm{ICE}}\right)$ are calculated according to the equation (7). The calculation follows the following steps:

- Choice of a wing loading $(\mathrm{W} / \mathrm{S}=\overline{\mathrm{W} / \mathrm{S}})$;

- Calculation of the minimum specific power allowable for that wing loading (as defined in Sect. 3.3);

- Calculation of the propulsion masses taking into account the efficiency of the propulsion chain.

Parallel

$$
\left\{\begin{array}{l}
\mathrm{M}_{\mathrm{EL}}=\left.\max \left\{\frac{\mathrm{P}}{\mathrm{MTOM}}\right\}\right|_{\frac{\mathrm{W}}{\mathrm{S}}=\frac{\mathrm{W}}{\mathrm{S}} \frac{\mathrm{H}_{\mathrm{P}}}{\eta_{\mathrm{EL}}} \frac{\mathrm{MTOM}}{\mathrm{EMPD}}} \\
\mathrm{M}_{\mathrm{ICE}}=\left.\max \left\{\frac{\mathrm{P}}{\mathrm{MTOM}}\right\}\right|_{\frac{\mathrm{W}}{\mathrm{S}}}=\frac{\overline{\mathrm{W}}}{\mathrm{S}} \frac{1-\mathrm{H}_{\mathrm{P}}}{\eta_{\mathrm{ICE}}} \frac{\mathrm{MTOM}}{\mathrm{ICEPD}}
\end{array}\right.
$$

Serial

$$
\left\{\begin{array}{l}
\mathrm{M}_{\mathrm{EL}}=\left.\max \left\{\frac{\mathrm{P}}{\mathrm{MTOM}}\right\}\right|_{\frac{\mathrm{W}}{\mathrm{S}}=\frac{\mathrm{W}}{\mathrm{S}}} \frac{1}{\eta_{\mathrm{EL}}} \frac{\mathrm{MTOM}}{\mathrm{EMPD}} \\
\mathrm{M}_{\mathrm{ICE}}=\left.\max \left\{\frac{\mathrm{P}}{\mathrm{MTOM}}\right\}\right|_{\frac{\mathrm{W}}{\mathrm{S}}}=\frac{\mathrm{W}}{\mathrm{S}} \frac{1-\mathrm{H}_{\mathrm{P}}}{\eta_{\mathrm{ICE}}} \frac{\mathrm{MTOM}}{\mathrm{ICEPD}}
\end{array}\right.
$$

$\eta_{\mathrm{EL}}$ and $\eta_{\mathrm{ICE}}$ are the efficiencies of the electric and thermal chains, respectively. EMPD and ICEPD are the electric motor power density and the internal combustion engine power density, respectively. The efficiency of the electrical and thermal chains depends on the selected hybrid architecture. The relationships are displayed in Table 2.
Table 3. Comparison between the ATR42-600 and the test configuration aircraft in case of no-hybridization.

\begin{tabular}{lll}
\hline & ATR42-600 & Test config. \\
\hline OEW/MTOM & $62.9 \%$ & $61.91 \%$ \\
Fuel mass $/$ MTOM & $12.58 \%$ & $12.17 \%$ \\
MTOM/S $\left(\mathrm{kg} / \mathrm{m}^{2}\right)$ & 341.3 & 341.3 \\
AR & 11 & 11 \\
\hline
\end{tabular}

$\eta_{\mathrm{B}}$ is the efficiency of the battery; $\eta_{\mathrm{esc}}$ is the efficiency of the electronic speed control of the electric motor; $\eta_{\mathrm{gb}}$ is the efficiency of the gearbox, and $\eta_{\text {prop }}$ is the efficiency of the propeller. We assumed a specific power of $5.3 \mathrm{~kW} / \mathrm{kg}$ (EMPD) for the electric motor (electronic speed controller has been included in it). The calculation of the mass associated to battery management system and wiring has been done as well: a specific power equal to $24.6 \mathrm{~kW} / \mathrm{kg}$ and $352 \mathrm{Wm} / \mathrm{kg}$ has been considered, respectively $[38,39]$. The battery package and fuel mass $\left(\mathrm{M}_{\mathrm{BATT}}+\mathrm{M}_{\mathrm{FUEL}}\right)$ comes from the "Performance analysis" block.

\subsection{Test case}

To test the software THEA-CODE, the degree of hybridization has been set equal to zero, so a first comparison between the test tube-and-wing configuration and the ATR42-600 has been done. The main results are displayed in Table 3.

The results show a quite satisfying agreement between the ATR42-600 and the test configuration in terms of mass and dimensions.

\section{Results}

In this section, the main results of THEA-CODE are presented. In the Section 4.1 the TLARs for the design of a Prandtl Plane regional aircraft have been shown; in the Section 4.2, a comparison between the two hybrid architectures (serial and parallel) has been performed. In the Section 4.3, the main results on Prandtl Plane configurations varying the BED have been obtained.

\subsection{Prandtl Plane TLARs definition}

In this paper, the electrification of a regional Prandtl Plane has been considered (an example is depicted in "Fig. 8"); for this case of study, regional Prandtl Plane TLARs are similar to the ATR42 TLARs reported in [40].

The TLARs are displayed in Table 4; the degree of hybridization ranges from 0 to 1 , and the wing loading ranges from 140 to $380 \mathrm{~kg} / \mathrm{m}^{2}$.

\subsection{Comparison serial-parallel hybrid-electric architectures}

According to the TLARs, several Prandtl Plane configurations have been evaluated for both serial and parallel 


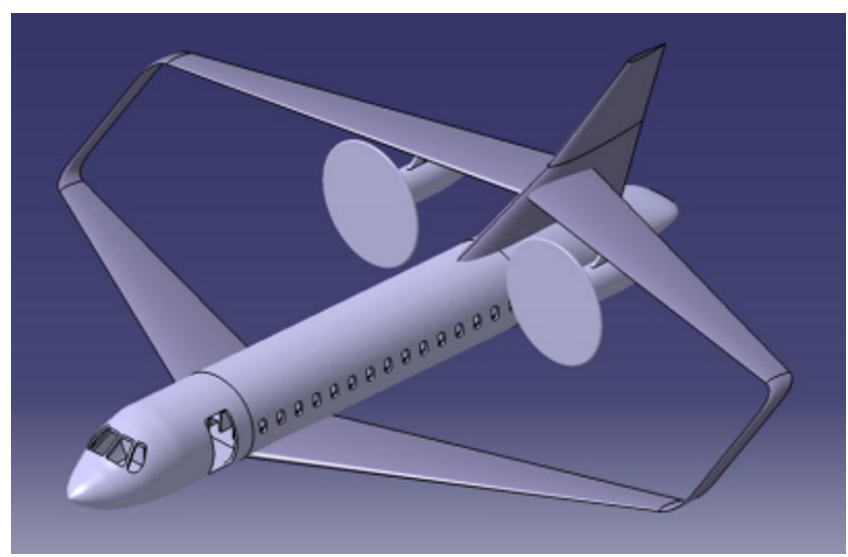

Fig. 8. An example of Prandtl Plane regional aircraft.

\section{Serial Hybrid Electric}

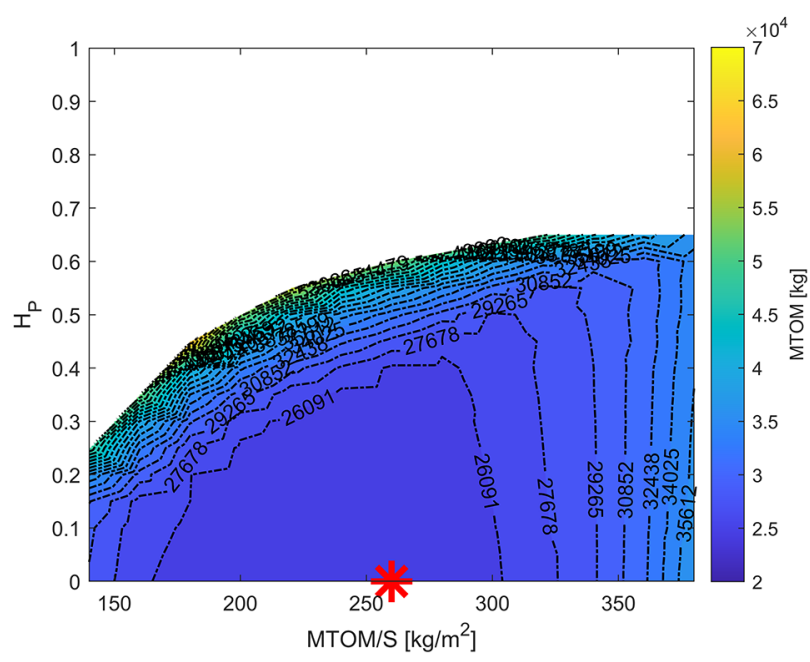

Table 4. TLARs for the regional Prandtl Plane aircraft.

\begin{tabular}{ll}
\hline Number of seats & 48 \\
\hline Cruise mach & 0.45 \\
Cruise altitude & $200 \mathrm{FL}$ \\
Mission range & $716 \mathrm{~nm}$ \\
Take-off field length & $1165 \mathrm{~m}$ \\
Landing field length & $1126 \mathrm{~m}$ \\
BED & $500-1000-1500 \mathrm{Wh} / \mathrm{kg}$ \\
\hline
\end{tabular}

Fig. 9. Comparison of serial and parallel hybrid architecture in terms of MTOM.

architecture. From the comparison comes out that the parallel architecture is a more convenient configuration from several points of view. The design space available is larger (higher degree of hybridization can be achievable), so more solutions can be explored. Moreover, the MTOM of the configurations as well as the fuel burnt, and the $\mathrm{CO}_{2}$ emissions are lower for the parallel hybrid architecture. We can assume that this behaviour is related to the higher efficiency (see Tab. 2) of the parallel hybrid architecture [41]; in fact, the lower efficiency of the propulsion system produces an higher energy demand to the electric and thermal part, causing an increase of the mass of the propulsion system, hence the total mass of the aircraft. In Figure 9 the comparison between the two architectures in terms of MTOM is depicted.

However, if the battery energy density is not enough, it is not possible to exploit all the design space. It is well highlighted in the mass breakdown shown in "Figure 10"; if the degree of hybridization increases, the battery mass and the MTOM increase as well. The reason of this behaviour is related to the low BED: for low values, the battery supplies energy in take-off and climb; as soon as the degree of hybridization increases the energy request to the battery increases as well in cruise (the most energy demanding phase), so the total mass of the aircraft increases dramatically. The histogram in "Figure 10" has been normalized according to the equation (8); the term MTOM (0) refers to the mass of the no-hybrid aircraft; the term MTOM $\left(\mathrm{H}_{\mathrm{P}}\right)$ refers to the mass of the hybrid aircraft at a specific degree of hybridization.

$$
\chi=\frac{\operatorname{MTOM}\left(\mathrm{H}_{\mathrm{P}}\right)}{\operatorname{MTOM}(0)}
$$

Referring again to the "Figure 9", it can be noted that higher degree of hybridization can be achieved for higher wing loading. This effect is mainly related to the energy demand in cruise; as shown in Figures 4 and 5, low wing 


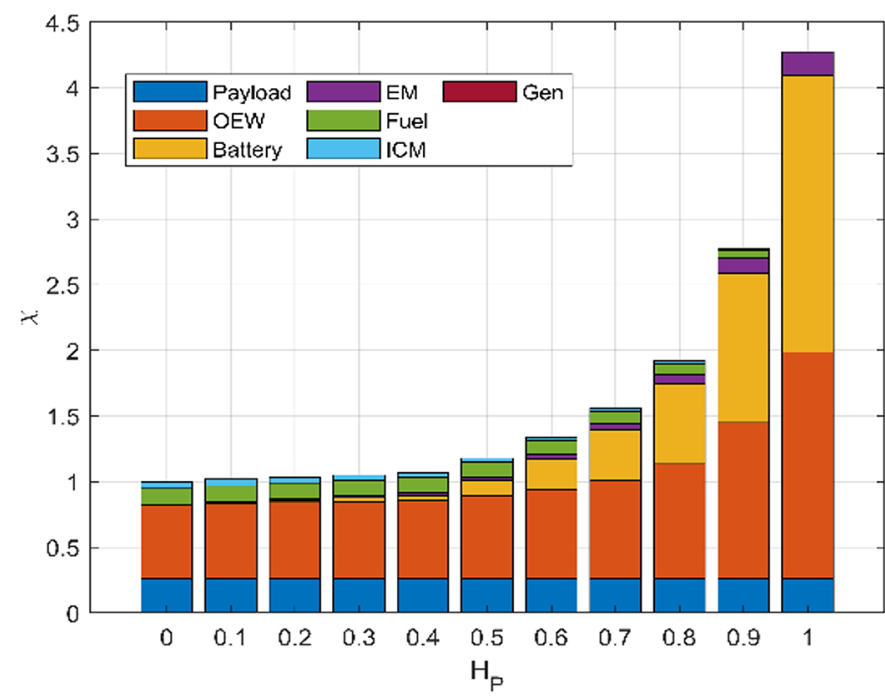

Fig. 10. Mass breakdown for a parallel hybrid-electric architecture with a constant wing load of $290 \mathrm{~kg} / \mathrm{m}^{2}$ and a BED = $1000 \mathrm{Wh} / \mathrm{kg}$ [19].

Table 5. Sources of electrical energy production in EU.

\begin{tabular}{lll}
\hline & $\begin{array}{l}\text { \% production } \\
\text { in EU }\end{array}$ & $\begin{array}{l}\text { Non direct } \mathrm{CO}_{2} \\
\text { emission } \\
(\mathrm{g} / \mathrm{kWh})\end{array}$ \\
\hline Coal $\left(\xi_{\text {coal }}\right)$ & 18.4 & 1000 \\
Oil $\left(\xi_{\text {oil }}\right)$ & 8.4 & 800 \\
Natural gas $\left(\xi_{\text {gas }}\right)$ & 15.2 & 500 \\
Nuclear Power $\left(\xi_{\text {np }}\right)$ & 29.3 & 50 \\
Renewable resources $\left(\xi_{\text {re }}\right)$ & 25.4 & 50 \\
\hline
\end{tabular}

loading requires high energy demand in cruise, so also low degrees of hybridization imply a high energy demand to the battery causing a rapid increase of the aircraft mass.

Regarding the $\mathrm{CO}_{2}$ emissions, both direct (due to the fuel burnt during the flight) and indirect emissions (due to the generation of the electrical energy) have been considered, so, in case of full-electric aircraft, the $\mathrm{CO}_{2}$ emissions are not zero. The indirect emission has been calculated according to the IATA documents [42,43]. The main sources of electrical energy production are coal, oil, natural gas, nuclear power and renewable energies. The percentage distributions and their $\mathrm{CO}_{2}$ emissions are displayed in Table 5.

$\varepsilon_{i}(i=$ coal, oil, ecc...) is the percentage production of the electrical energy in EU, whereas $\xi_{\mathrm{i}}$ is the emission related to that source for the electrical energy production. According to the previous data, the equation (9) has been used to evaluate the current non direct $\mathrm{CO}_{2}$ emissions.

$$
\xi_{\text {ind }}=\xi_{\text {coal }} \varepsilon_{\text {coal }}+\xi_{\text {oil }} \varepsilon_{\text {oil }}+\xi_{\text {gas }} \varepsilon_{\text {gas }}+\xi_{\mathrm{np}} \varepsilon_{\mathrm{cp}}+\xi_{\mathrm{re}} \varepsilon_{\mathrm{re}}
$$

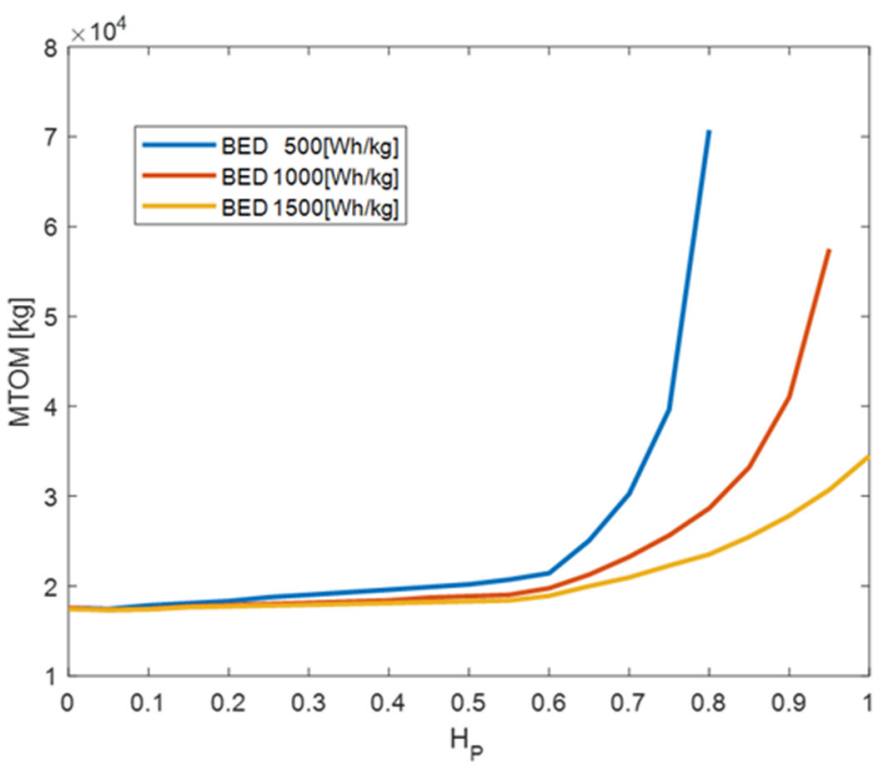

Fig. 11. Plot of the MTOM vs $H_{P}$ graph for a box-wing configuration at $\mathrm{W} / \mathrm{S}=350 \mathrm{~kg} / \mathrm{m}^{2}$, varying the battery energy density.

The current direct emissions are calculated assuming a value of $3150 \mathrm{~g}$ of $\mathrm{CO}_{2}$ for each $\mathrm{kg}$ of fuel burnt. In the case of BED equal to $1000 \mathrm{Wh} / \mathrm{kg}$, the emissions coming from the electrical energy production are about $354 \mathrm{~g}$ of $\mathrm{CO}_{2}$ for each kilogram of battery by using equation (9).

\subsection{Parallel hybrid-electric aircraft}

In "Figure 12" are reported the results for Prandtl Plane configurations at different BED values. The left and right figures differ for the energy density of the battery, which is $500 \mathrm{Wh} / \mathrm{kg}$ (achievable before 2035 [18]) and $1500 \mathrm{Wh} / \mathrm{kg}$ (achievable after 2035 [18]), respectively. For the configurations with the lowest BED, the region of the feasible solutions is smaller than the one with higher BED; for low values of BED no hybrid configurations (with HP > 0.8) have been found. This happens because a big part of the energy demand comes from the battery and, if the BED is low, it leads to a very high battery mass with a subsequent snowball effect on the total mass of the aircraft. In addition to this, the space allocation of the battery is very critical. The same effect is well represented in Figure 11, where the wing loading $\left(350 \mathrm{~kg} / \mathrm{m}^{2}\right)$ is constant, and the MTOM is represented as a function of the degree of hybridization for a set of battery energy densities.

The "Figure 12a and 12b" show how the MTOM changes; for both cases, the configuration with minimum MTOM corresponds to a no-hybrid aircraft. This result is mainly related to the lower value of the BED than the aviation fuel energy density (about $12000 \mathrm{Wh} / \mathrm{kg}$ [15]). The "Figure 12c and 12d" show the fuel burnt mass; for the configurations with the lowest BED ("Fig. 12c"), the minimum fuel burnt is reached in no-hybridization configuration because of the high weight penalty of the 

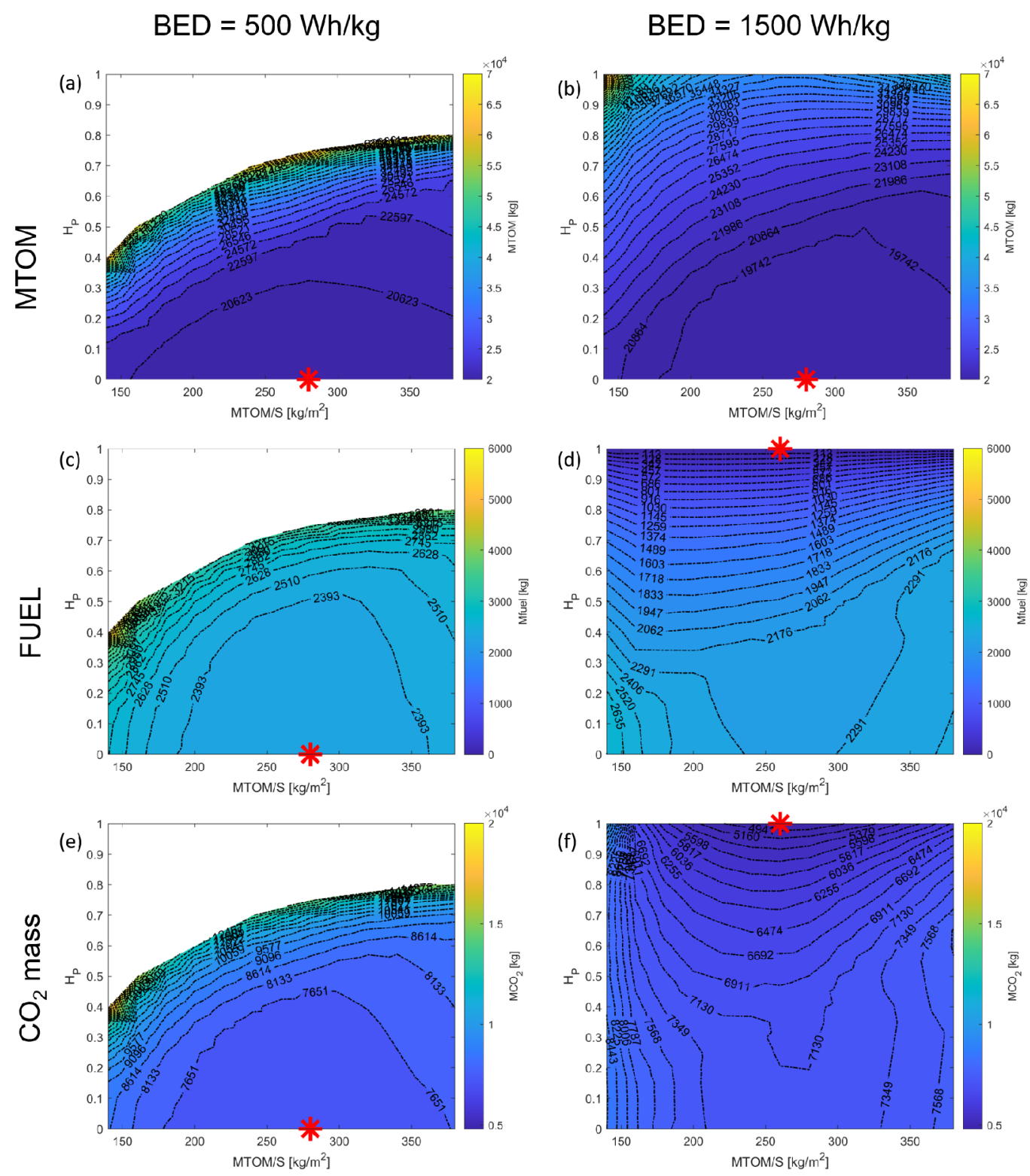

Fig. 12. MTOM, duel burnt and $\mathrm{CO}_{2}$ production for box-wing configuration with $\mathrm{BED}=500 \mathrm{Wh} / \mathrm{kg}(\mathrm{left})$ and $\mathrm{BED}=1500 \mathrm{Wh} / \mathrm{kg}$ (right).

hybrid ones. Increasing the BED, it is possible to reach a full-electric aircraft reducing the fuel to zero ("Fig. 12d") at the expense of the MTOM. The "Figure 12e and $12 \mathrm{f}$ " show the $\mathrm{CO}_{2}$ emissions. For a given wing loading, the $\mathrm{CO}_{2}$ emission trend is strictly related to the BED: for low BED the $\mathrm{CO}_{2}$ emissions increase if $\mathrm{HP}$ increases; on the contrary, for high $\mathrm{BED}$, the reverse happens. This trend is strictly related to the trend depicted in Figures 10-12c and 12d. If $\mathrm{HP}$ increases:

- Figure 10 shows that the battery weight becomes a relevant component in the mass break-down;

- Figure 11 shows that the MTOM increases dramatically. - Figure 12c and 12d shows that fuel consumption increases with $\mathrm{BED}=500 \mathrm{Wh} / \mathrm{kg}$.
Since $\mathrm{CO}_{2}$ emission are strictly related to fuel consumption, all the previous information tell us that the $\mathrm{CO}_{2}$ emissions increase as well. Conversely, for a high value of $\mathrm{BED}$, a fuel reduction happens if $\mathrm{HP}$ increases, so the $\mathrm{CO}_{2}$ emission decreases.

For high BED, full-electric configurations result in cleaner configurations although without reaching the goal of zero emissions. It is worth to note that the results obtained for the $\mathrm{CO}_{2}$ emissions are related to the current sources to produce electrical energy in the EU, if more renewable resources will be used, higher improvements will be expected. "Figure 12" shows how the optimal configurations, intended as the one at minimum MTOM, fuel burnt and $\mathrm{CO}_{2}$ emissions, do not coincide at high BED. 


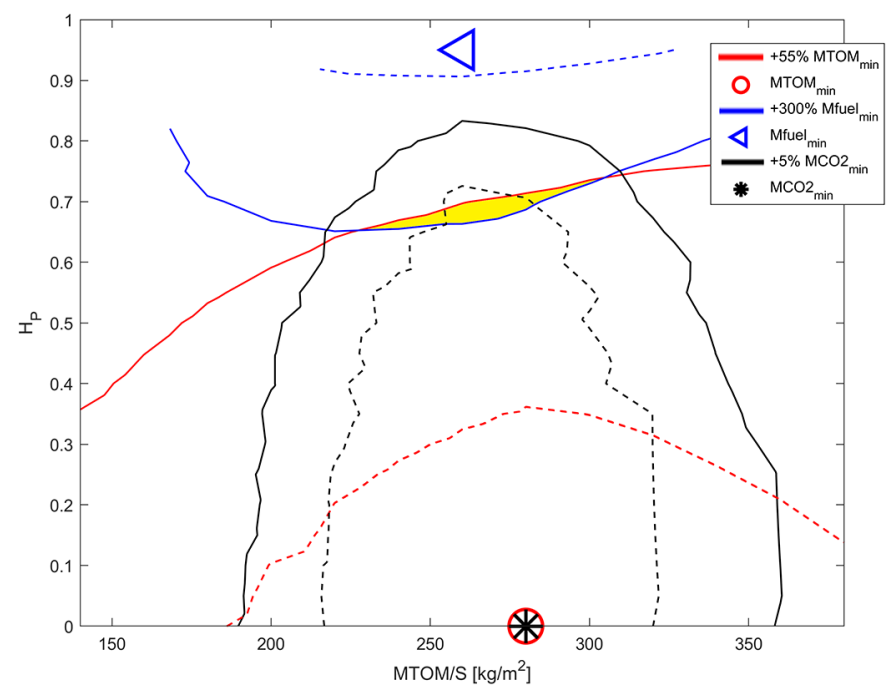

Fig. 13. The region (yellow) of the possible aircraft configurations for $\mathrm{BED}=1000 \mathrm{Wh} / \mathrm{kg}$.

From an aircraft design perspective, this fact affects the choice of the parameters for the solution of best compromise. Ideally, the best solutions have to be intended as the ones close as much as possible to the optimal configurations. In case of high BED, a good configuration must be a compromise between the configuration at minimum MTOM and minimum fuel burnt. A set of solutions can be graphically located and are shown in Figure 13: the red line indicates the configurations with a MTOM higher than the reference configuration (which minimizes the MTOM); in the same way the blue (fuel) and black $\left(\mathrm{CO}_{2}\right)$ lines indicates the configuration with higher fuel consumption and higher emissions, respectively. The intersections of the three regions create a shared region (yellow area) where the designer can change the design parameters (wing load and degree of hybridization) to obtain the solution of best compromise. For high BED, the optimal configurations are not so close each other, so a shared region is possible if at least one of the three parameters (MTOM, fuel burnt and $\mathrm{CO}_{2}$ ) is degraded with respect to its minimum value. If the designer considers very low degradations (dashed lines of Fig. 13), no intersection can be obtained. Degrading, for example, the fuel burnt and the MTOM, it is possible to define a set of possible solutions; nevertheless, the designer must take that a MTOM degradation implies an increase of direct cost into account. In the aircraft design perspective other parameters must be considered such as the aircraft utilization or the direct costs, which can lead to a different choice. An example of box-wing configuration based on THEA-CODE outcomes is depicted in Figure 14.

\section{Conclusion and future developments}

In this work, a new conceptual design tool called THEACODE has been presented. The tool can deal with the conceptual design of parallel and serial hybrid-electric architectures with conventional and unconventional
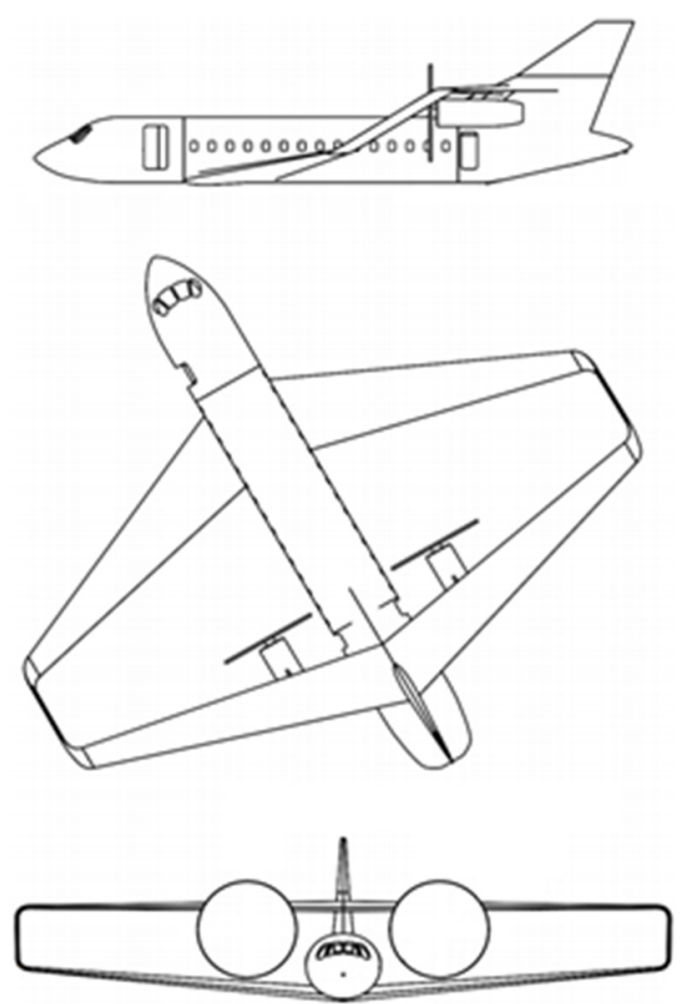

Fig. 14. Example of the tryptic of a configuration obtained by THEA-CODE.

airframes, such as the box-wing one here presented. The developed methodology is based on the classical aircraft design procedures, in which the Athena Vortex Lattice code AVL is used to evaluate aerodynamic performance in order to deal with unconventional configurations. Moreover, the code can calculate both direct and indirect $\mathrm{CO}_{2}$ emissions.

The preliminary results have shown that:

- Comparing the series and parallel hybrid electric aircraft, the latter allows to obtain better results in terms of MTOM, fuel burnt and emissions;

- Low BED reduces the design space; in fact, no high degree of hybridization can be achievable and only minor hybridization could be adopted (typically to cover takeoff and climb);

- High BED can allow a reduction of fuel burnt and $\mathrm{CO}_{2}$ emissions; nevertheless, the energy density is too much lower than the fuel one, and no reduction in weight can be obtained unless much better integration could be achieved;

- In case of full-electric aircraft, the total emissions are not zero since the indirect emissions for electrical energy production has been considered as well.

- In case of high BED, it is not possible to obtain a solution with minimum fuel consumption, emission and MTOM, so a best compromise solution must be chosen according other criteria such as direct cost.

Future developments of the code concern the implementation of the interactions between propellers and lifting surfaces, a structural model in order to improve weight 


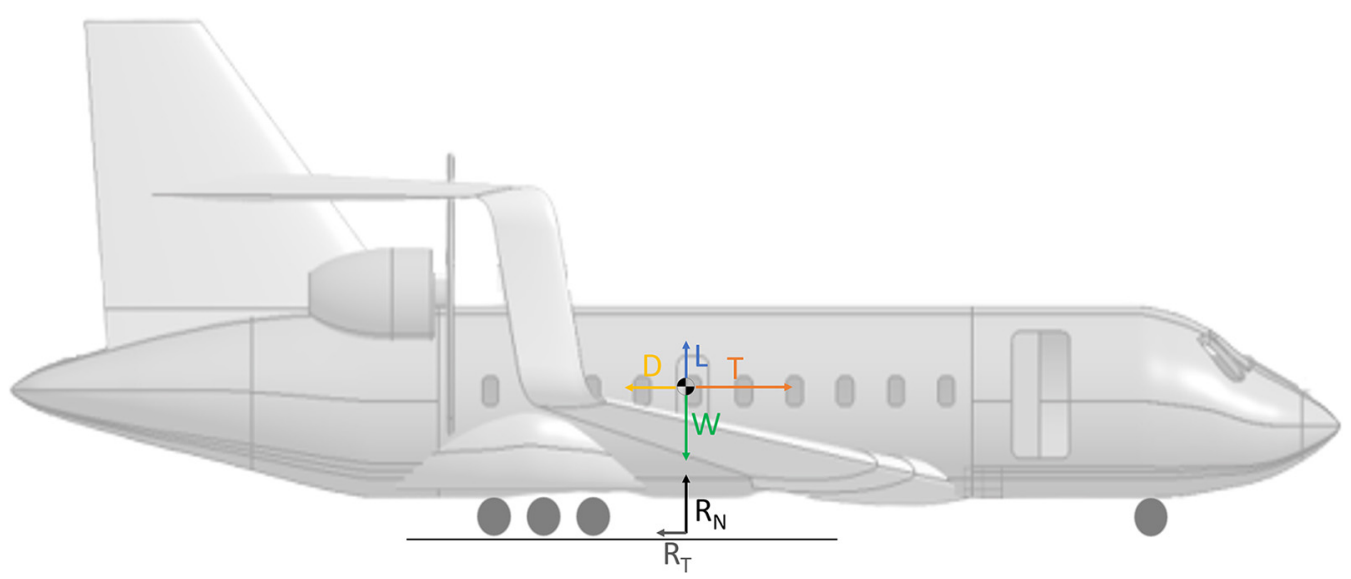

Fig. 15. Forces acting on the aircraft during the ground roll.

estimation, a design of a more accurate energy management strategy and the introduction of the distributed electric propulsion model.

\section{Appendix}

The take-off run can be split in three part: ground roll, rotation and lift-off. During the ground roll, the aircraft attitude remains constant with engine at full thrust; once the rotation speed has been reached, the aircraft rotates around the main landing gear by the elevator deflection; the lift-off phase starts in the moment in which the aircraft pulls the wheels of the ground.

In the ground roll phase, there are different forces acting on the aircraft (see Fig. 15):

- Aerodynamic forces as lift (L) and drag (D);

- Propulsive forces as the engine thrust (T);

- Reaction forces as the ground reaction.

The equation (10) is the first Newton's law in the ground roll.

$$
\mathrm{T}-\mathrm{D}-\mu(\mathrm{W}-\mathrm{L})=\frac{\mathrm{W}}{\mathrm{g}} \frac{\mathrm{dV}}{\mathrm{dt}}=\frac{\mathrm{W}}{\mathrm{g}} \frac{\mathrm{dV}}{\mathrm{ds}} \mathrm{V}
$$

By using the equation (10), it is possible to obtain a similar equation in terms of power, as reported in equation (11)

$$
\eta_{P} \mathrm{P}-\mathrm{DV}-\mu \mathrm{V}(\mathrm{W}-\mathrm{L})=\frac{\mathrm{W}}{\mathrm{g}} \mathrm{V}^{2} \frac{\mathrm{dV}}{\mathrm{ds}}
$$

For the propeller efficiency, it is reasonable to assume a linear relationship

$$
\eta_{P}=\bar{\eta}_{p} \frac{\mathrm{V}}{\mathrm{V}_{2}}
$$

Combining equations (11) and (12) the ground roll distance $\left(\mathrm{S}_{\mathrm{GR}}\right)$ can be easily obtained

$$
\mathrm{S}_{\mathrm{GR}}=-\frac{\frac{\mathrm{W}}{S}}{\rho \mathrm{g}\left(\mathrm{C}_{\mathrm{D}}-\mu \mathrm{C}_{\mathrm{L}}\right)} \log \left(1-\frac{\mathrm{k}_{\mathrm{V}_{\mathrm{R}}}^{2}\left(\mathrm{C}_{\mathrm{D}}-\mu \mathrm{C}_{\mathrm{L}}\right)}{\left(\frac{\overline{\eta_{P}}}{\mathrm{~V}_{2}}\left(\frac{\mathrm{P}}{W}\right)-\mu\right) \mathrm{C}_{\mathrm{Lmax}}}\right)
$$

In the rotation phase, the distance covered by the aircraft can be calculated assuming a constant speed and a duration of about $3 \mathrm{~s}$ [36].

$$
\mathrm{S}_{\mathrm{R}}=\mathrm{V}_{\mathrm{R}} \mathrm{t}_{\mathrm{R}}
$$

In the lift-off phase, the aircraft pulls the wheel off the ground and its path can be approximated by a circular trajectory, so the equation (15) can be used to evaluate the covered horizontal distance (see Fig. 16).

$$
\left\{\begin{array}{l}
\mathrm{L}-\mathrm{W}=\frac{\mathrm{W}}{\mathrm{g}} \frac{\mathrm{V}_{2}^{2}}{\mathrm{R}} \\
\mathrm{R}(1-\cos \theta)=\mathrm{h} \\
\mathrm{S}_{\mathrm{LO}}=R \sin \theta
\end{array}\right.
$$

Rearranging the equation (15), the horizontal distance can be easily calculated

$$
\left\{\begin{array}{c}
R=\frac{\mathrm{k}_{\mathrm{V}_{2}}^{2} \frac{2 \mathrm{~W} / \mathrm{S}}{\rho \mathrm{C}_{\mathrm{Lmax}}}}{\mathrm{g}\left(\mathrm{n}_{\mathrm{z}}-1\right)} \\
\mathrm{S}_{\mathrm{LO}}=R \sqrt{1-\left(1-\frac{\mathrm{h}}{R}\right)^{2}}
\end{array}\right.
$$

Combining the equations $(13,14,16)$, the total distance covered by the aircraft in take-off is given by the equation (17)

$$
\mathrm{S}_{\mathrm{TO}}=\mathrm{S}_{\mathrm{GR}}+\mathrm{S}_{\mathrm{R}}+\mathrm{S}_{\mathrm{LO}}
$$




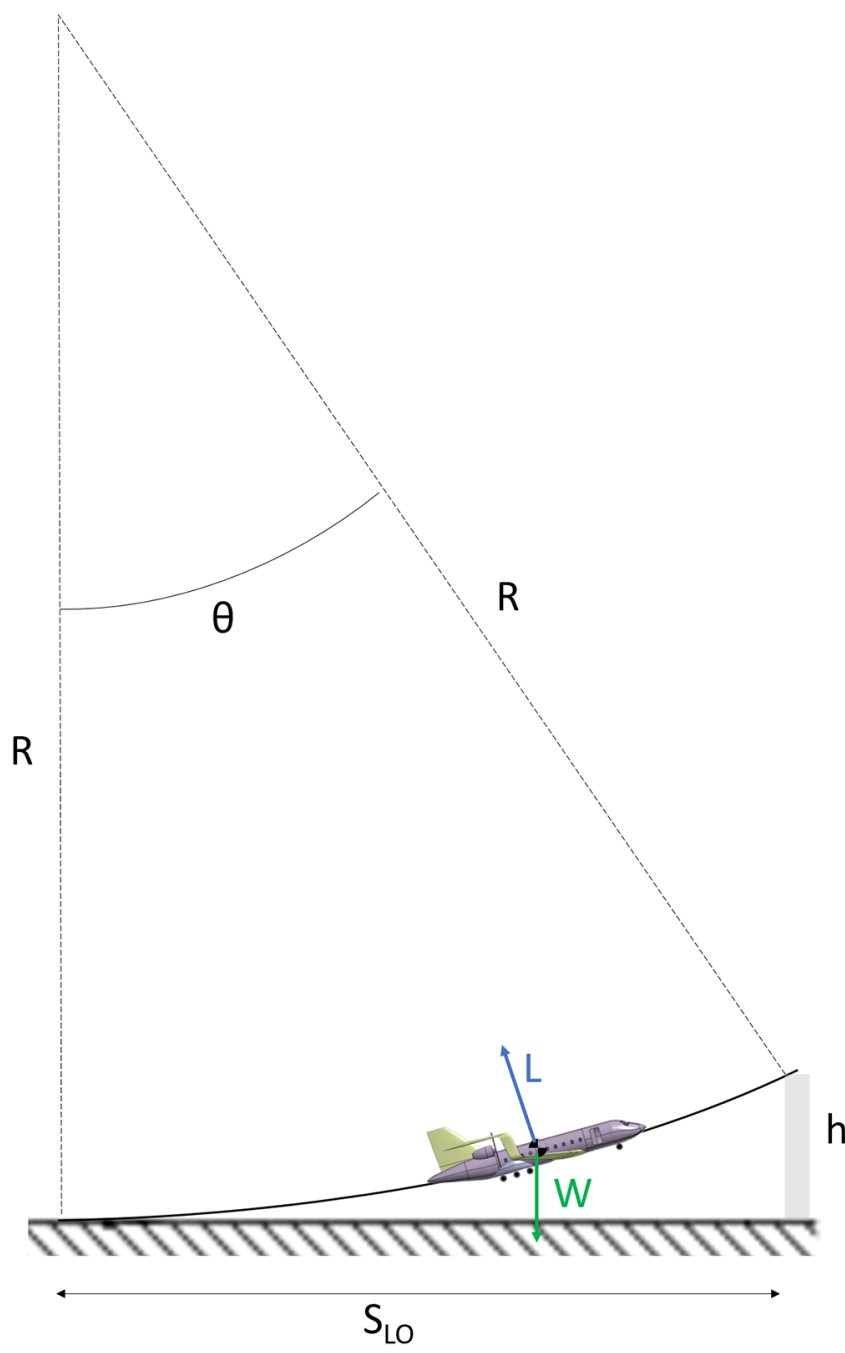

Fig. 16. Circular trajectory in the lift-off phase.

The covered distance must be lower than the take-off length $\left(\mathrm{L}_{\mathrm{TO}}\right)$ given by the TLARs, so

$$
\mathrm{S}_{\mathrm{TO}} \leq \frac{\mathrm{L}_{\mathrm{TO}}}{\sigma}
$$

By substituting the equations $(13,14,16)$ in equation (18), the relationship between wing loading and specific power can be obtained

$$
\begin{aligned}
\left(\frac{\mathrm{P}}{W}\right)_{\mathrm{TO}} & \geq\left(\mu+\frac{\frac{\mathrm{k}_{\mathrm{V}_{\mathrm{R}}}^{2}\left(\mathrm{C}_{\mathrm{D}}-\mu \mathrm{C}_{\mathrm{L}}\right)}{\mathrm{C}_{\mathrm{Lmax}}}}{1-\mathrm{e}^{-\rho \mathrm{g}\left(\mathrm{C}_{\mathrm{D}}-\mu \mathrm{C}_{\mathrm{L}}\right)\left(\frac{\mathrm{L}_{\mathrm{TO}}}{\sigma}-\mathrm{S}_{\mathrm{R}}-\mathrm{S}_{\mathrm{LO}}\right) /(\mathrm{W} / \mathrm{S})}}\right) \\
& \times \sqrt{\frac{2(\mathrm{~W} / \mathrm{S})}{\rho \mathrm{C}_{\mathrm{Lmax}}}} \mathrm{k}_{\mathrm{V}_{2}}
\end{aligned}
$$

Equation (19) is one of the achievements of the research here presented and represents, to authors' knowledge, a

\begin{tabular}{|c|c|}
\hline $\mathrm{b}$ & Wingspan [m] \\
\hline BED & Battery Energy Density [Wh $/ \mathrm{kg}]$ \\
\hline $\mathrm{c}$ & Wingchord [m] \\
\hline $\mathrm{Cd}$ & Airfoil drag coefficient \\
\hline $\mathrm{C}_{\mathrm{D}}$ & Aircraft drag coefficient \\
\hline $\mathrm{C}_{\mathrm{L}}$ & Aircraft lift coefficient \\
\hline $\mathrm{C}_{\text {Lmax }}$ & Aircraft maximum lift coefficient \\
\hline $\mathrm{D}$ & $\operatorname{Drag}[\mathrm{N}]$ \\
\hline $\mathrm{Df}_{\text {wing }}$ & Parasite wing drag $[\mathrm{N}]$ \\
\hline EMPD & Electric Motor Power Density [W $/ \mathrm{kg}]$ \\
\hline FAR & Federal Aviation Regulation \\
\hline $\mathrm{g}$ & standard gravity $\left[\mathrm{m} / \mathrm{s}^{2}\right]$ \\
\hline HEA & Hybrid Electric Aircraft \\
\hline $\mathrm{H}_{\mathrm{P}}$ & Degree of hybridization \\
\hline ICEPD & $\begin{array}{l}\text { Internal Combustion Engine Power Density } \\
{[\mathrm{W} / \mathrm{kg}]}\end{array}$ \\
\hline $\mathrm{k}_{\mathrm{V} 2}$ & Ratio between $V_{R}$ and stall speed \\
\hline $\mathrm{K}_{\mathrm{VR}}$ & $\begin{array}{l}\text { Ratio between rotation speed and stall speed } \\
\text { in take-off }\end{array}$ \\
\hline $\mathrm{k}_{\mathrm{VR}}$ & Ratio between $\mathrm{V}_{2}$ and stall speed \\
\hline $\mathrm{L}$ & Lift $[\mathrm{N}]$ \\
\hline $\mathrm{L}_{\mathrm{TO}}$ & Take-off field length available [m] \\
\hline $\mathrm{M}_{\mathrm{EL}}$ & Electric motor mass $[\mathrm{kg}]$ \\
\hline $\mathrm{M}_{\mathrm{ICE}}$ & Internal combustion engine mass [kg] \\
\hline $\mathrm{M}_{\text {OPIT }}$ & Operating items mass $[\mathrm{kg}]$ \\
\hline $\mathrm{M}_{\mathrm{STRUCT}}$ & Structural mass $[\mathrm{kg}]$ \\
\hline $\mathrm{M}_{\text {sys }}$ & Subsystem mass [kg] \\
\hline MTOM & Maximum take-off Mass [kg] \\
\hline $\mathrm{MTOM} / \mathrm{S}$ & Wing loading $\left[\mathrm{kg} / \mathrm{m}^{2}\right]$ \\
\hline $\mathrm{n}_{\mathrm{z}}$ & Vertical load factor \\
\hline OEM & Operative Empty Mass [kg] \\
\hline $\mathrm{P}$ & Power $[W]$ \\
\hline $\mathrm{P} / \mathrm{MTOM}$ & Specific power $[\mathrm{W} / \mathrm{kg}]$ \\
\hline $\mathrm{P}_{\mathrm{ICE}}$ & Internal combustion engine power [W] \\
\hline$P_{\text {REQ }}$ & Power requested for each mission [W] \\
\hline $\mathrm{PSFC}$ & Power specifi fuel consumption [kg/Wh] \\
\hline $\mathrm{P}_{\mathrm{TOT}}$ & Total power \\
\hline$(\mathrm{P} / \mathrm{W})_{\mathrm{I}}$ & $\begin{array}{l}\text { Specific power required to the engine at the } \\
\text { i-th phase }\end{array}$ \\
\hline
\end{tabular}
novel approach the design of propeller driven aircraft.

\section{List of symbols}

$(\mathrm{P} / \mathrm{W}) \mathrm{TO}$ Specific power required to the engine at the take-off

$\mathrm{S}_{\mathrm{LO}} \quad$ Distance covered in lift-off

$\mathrm{S}_{\mathrm{R}} \quad$ Distance covered in ground roll

$\mathrm{S}_{\mathrm{R}} \quad$ Distance covered in rotation

$\mathrm{S}_{\mathrm{TO}} \quad$ Distance covered in take-off

TLARs Top-Level Aircraft Requirements

$t_{R} \quad$ Time of the rotation phase

$\mathrm{V} \quad$ True air speed

$\mathrm{V}_{2} \quad$ Aircraft speed at the end of the take-off

$\mathrm{V}_{\mathrm{R}} \quad$ Aircraft speed at the end of the ground roll

$\mathrm{W} \quad$ Aircraft weight

$\varepsilon \quad$ Percentage production of the electrical energy in EU 


$\begin{array}{ll}\eta_{\mathrm{EL}} & \text { Electric chain efficiency } \\ \eta_{\mathrm{ICE}} & \text { Thermal chain efficiency } \\ \eta_{\mathrm{P}} & \text { Propeller efficiency } \\ \bar{\eta}_{\mathrm{P}} & \text { Propeller efficiency at } \mathrm{V}_{2} \\ \mu & \text { Rolling friction coefficient } \\ \xi & \text { Emission related to a specific source for the } \\ & \text { electrical energy production } \\ \rho & \text { Air density } \\ \sigma & \text { Security factor } \\ \chi & \text { Ratio between hybrid and thermal aircraft } \\ & \text { weight }\end{array}$

\section{References}

[1] https://climate.nasa.gov/causes/ (accessed on 21 October 2020)

[2] UN Climate Change Conference (December 2019). https:// unfccc.int / cop25

[3] D.S. Lee, D.W. Fahey, P.M. Forster, P.J. Newton, R.C.N. Wit, L.L. Lim, B. Owen, R. Sausen, Robert, Aviation and global climate change in the 21st century, Atmospheric Environment 43, 3520-3537 (2009)

[4] International Energy Agency, $\mathrm{CO}_{2}$ Emissions from Fuel Combustion (2017)

[5] A.W. Schäfer, S.R.H. Barrett, K. Doyme et al., Technological, economic and environmental prospects of all-electric aircraft. Nat Energy 4, 160-166 (2019)

[6] Airbus Global Market Forecast 2017-2037 (Airbus Commercial Aircraft, Toulouse, 2017)

[7] Boeing Current Market Outlook 2017-2036 (Boeing Commercial Airplanes, Seattle, 2017)

[8] R.M. Arnaldo Valdés, S. Burmaoglu, T. Vincenzo, L.M. Braga da Costa Campos, L. Mattera, V.F. Gomez Comendador, Flight path 2050 and ACARE goals for maintaining and extending industrial leadership in aviation: a map of the aviation technology space, Sustainability 11, 2065 (2019)

[9] European Commission, Flightpath 2050 Europe's vision for aviation, Technical report. Luxembourg, Belgium: Publications Office of the European Union. http://ec.europa.eu/ transport/modes/air/doc/flightpath2050.pdf/ (2007)

[10] ACARE-Advisory Council for Aviation Research and Innovation in Europe, (2017). https://www.acare4europe. org/sites/acare4europe.org/files/document/ACARE-Strate gic-Research-Innovation-Volume-1.pdf (accessed on 21 October 2020)

[11] PARSIFAL (Prandtl plane ARchitecture for the Sustainable Improvement of Future AirpLanes). http://parsifalproject. $\mathrm{eu} /$ (accessed on 21 October 2020)

[12] ARTEM (Aircraft noise Reduction Technologies and related Environmental iMpact). https://www.dlr.de/at/en/desk topdefault.aspx/tabid-12792/22417_read-51601/ (accessed on 21 October 2020)

[13] MAHEPA (Modular Approach to Hybrid Electric Propulsion Architecture). https://mahepa.eu/

[14] V. Viswanathan, B.M. Knapp, Potential for electric aircraft. Nat Sustain 2, 88-89 (2019)
[15] National Academies of Sciences, Engineering, and Medicine, Commercial Aircraft Propulsion and Energy Systems Research: Reducing Global Carbon Emissions. Washington, DC: The National Academies Press, 2016

[16] B. Brelje, J. Martins, Electric, hybrid, and turboelectric fixed-wing aircraft: a review of concepts, models, and design approaches, Progress in Aerospace Sciences 104, 1-19 (2019)

[17] H. Kuhn, A. Seitz, L. Lorenz, A.T. Isikveren, A. Sizmann, B. Luftfahrt, Progress and perspectives of electric air transport, 28th International Congress of the Aeronautical Sciences, ICAS, Brisbane, Australia, 2012

[18] H. Kuhn, A. Sizmann, Fundamental Prerequisites of Electric Flying. Proceedings of the German Aerospace Congress (DLRK), Berlin, Germany, 2012

[19] A.R. Gnadt, R.L. Speth, J.S. Sabnis, S.R.H. Barrett, Technical and environmental assessment of all-electric 180-passenger commercial aircraft, Progress in Aerospace Sciences (2018). doi: 10.1016/j.paerosci.2018.11.002.

[20] D. Ciliberti, F. Orefice, P. Vecchia, F. Nicolosi, S. Corcione, Salvatore, An approach to preliminary sizing of turboelectric aircraft with distributed propulsion, AIDAA Congress, Rome, 2019

[21] R. De Vries, M. Brown, R. Vos, A preliminary sizing method for hybrid-electric aircraft including aero-propulsive interaction effects, Aviation Technology, Integration, and Operations Conference, 2018

[22] L. Trainelli, F. Salucci, N. Rossi, C.E.D. Riboldi, A. Rolando, Preliminary Sizing and Energy Management of Serial Hybrid-Electric Airplanes, AIDAA Congress, Rome, 2019

[23] M. Strack, G.P. Chiozzotto, M. Iwanizki, M. Plohr, M. Kuhn, Conceptual Design Assessment of Advanced Hybrid Electric Turboprop Aircraft Configurations, in: Proceedings of the 17th AIAA Aviation Technology, Integration, and Operations Conference, Denver, CO, USA, 5-9 June 2017

[24] M.B.J. Voskuijl, A.G. Rao, Analysis and design of hybrid electric regional turboprop aircraft, CEAS Aeronautical Journal 9, 15-25 (2018)

[25] A. Sgueglia, P. Schmollgruber, N. Bartoli, E. Benard, J. Morlier, J. Jasa, J.S. Gray, Multidisciplinary design optimization framework with coupled derivative computation for hybrid aircraft, Journal of Aircraft 57, 715-729 (2020)

[26] A. Frediani, The Prandtl wing. VKI lecture series: Innovative Configurations and Advanced Concepts for Future Civil transport Aircraft, 6-10 June 2005

[27] L. Prandtl, Induced drag of multiplanes, NACA-TN-182, URL: http://ntrs.nasa.gov/search.jsp?R=19930080964 (1924)

[28] A. Frediani, V. Cipolla, F. Oliviero, Design of a prototype of light amphibious Prandtl Plane, 56th AIAA/ASCE/AHS/ ASC Structures, Structural Dynamics, and Materials Conference, 2015, p. 0700

[29] D.F. Finger, C. Braun, C. Bil, An initial sizing methodology for hybrid-electric light aircraft, Aviation Technology Integration and Operations Conference, Atlanta, GA, USA, 2018, June 25-29

[30] http://web.mit.edu/drela/Public/web/avl/ (accessed on 10 January 2020)

[31] https://web.mit.edu/drela/Public/web/xfoil/ (accessed on 10 January 2020) 
[32] D. Raymer, Aircraft design: a conceptual approach, Sixth Edition, Washington, D.C.: American Institute of Aeronautics and Astronautics, 2018, 10.2514/4.104909

[33] J.D. Mattingly, W.H. Heiser, D.H. Daley, Aircraft engine design, American Institute of Aeronautics and Astronautics, Washington, DC, 1987

[34] T. Nam, A generalized sizing method for revolutionary concepts under probabilistic design constraints, Ph.D thesis, Georgia Institute of Technology, Atlanta, 2007

[35] Airbus Industry, Getting to Grips with Aircraft Performance, Flight Operations Support \& Line Assistance (2002)

[36] A. Filippone, Advanced aircraft flight performance, Cambridge University Press, 2012

[37] D.P. Wells, B.L. Horvath, L.A. McCullers, The flight optimization system weights estimation method, Tech. Rep. (2017)
[38] S. Stückl, Methods for the design and evaluation of future aircraft concepts utilizing electric propulsion systems, PhD Dissertation, Technische Universität München, 2016

[39] PROSIB Project, deliverable 4.1.1, University of Naples, Electric power storage sytems: future trends, technincal characteristics and performance, 2020

[40] http://www.atraircraft.com/products/ATR-42-600.html (accessed 09 January 2020)

[41] T. Hofman, Alternative fuels and advanced vehicle technologies for improved environmental performance, Woodhead Publishing, 2014, pp. 567-581

[42] Eurostat, Energy statistics, 2017 edition

[43] IATA, IATA Carbon Offset Program, Frequently asked question, version 10.1, (2020)

Cite this article as: G. Palaia, D. Zanetti, K. Abu Salem, V. Cipolla, V. Binante, THEA-CODE: a design tool for the conceptual design of hybrid-electric aircraft with conventional or unconventional airframe configurations, Mechanics \& Industry 22, 19 (2021) 